International Journal of Business Management and Economic Review

Vol. 4, No. 04; 2021

ISSN: 2581-4664

\title{
THE ROLE OF DATABASE SYSTEMS ON INNOVATION TOURISM: E-TOURISM IN INDONESIA
}

\author{
Khairun Mansyah, Kaslim Sugiono and Iskandar Muda \\ Master of Accounting, Universitas Sumatera Utara, Medan, Indonesia \\ http://doi.org/10.35409/IJBMER.2021.3283
}

\begin{abstract}
The Internet was designed to provide a simple and transparent end-to-end transfer service across a heterogeneous wired network infrastructure, allowing the exchange of information between two or more communication endpoints. A database is a system used to manage data on a computer system. There are several database work systems that have their own laws and ways of working. Data are arranged in various levels. In computer data are classified in a hierarchy. Modern data processing systems are designed to be general-purpose, in that they can handle a wide variety of different schemas, data types, and data distributions, and aim to provide efficient access to that data via the use of optimizers and cost models. This general purpose nature results in systems that do not take advantage of the characteristics of the particular application and data of the user. In general, E-Tourism is an application of information technology in the field of tourism in order to achieve effectiveness and efficiency in promoting the tourism sectors in Indonesia. By applying E-Tourism tourists and prospective ones are able to access tourism information fast and accurately.
\end{abstract}

Keyword: Internet, Database System, E-Tourism.

\section{INTRODUCTION}

One of the most important facilities that must be provided to support the tourism sector isthe need for information on tourist destinations and supporting facilities such as banks, supermarkets, ATMs and so on. The information provided must be supported by technology that can provide various access requests from users. This technology must be able to reach various levels of society.

Application of information systems and information dissemination in Indonesia tourism sector is one of the topical issues. In the 21st century, professional, personal life and business development are unthinkable without modern information systems. Realization of the tourist product requires such information systems that can provide information on tourist accommodation, booking and booking opportunities, transport rent, ticket reservations and other services within a short period of time.

Globalization process determines a rapidly expanding flow of information which results in building the information society. It is understandable that the emergence of information systems was determined by the level of computer technology evolution and changing expectations and needs of users. Despite the rapid development of information systems only since the middle of 


\section{International Journal of Business Management and Economic Review}

Vol. 4, No. 04; 2021

ISSN: 2581-4664

1990 they have become important in the activities of tourism and leisure organizations as most of them began to actively use the Internet (Novikov, 2007). For businesses, the Internet has made it possible, without much effort, to gain access to large groups of consumers, to provide specific information about the products offered, to securely disseminate details about their activities, to quickly and efficiently receive customer requests, to order the necessary services, and to reduce the financial costs of producing and distributing printed materials (Agarval, Prasad, 1999).

The tourism and leisure sector has become a mature market that needs changes in the transmission of information. Innovations, according to the researchers (Crawford et al.,

2005; Davidaviciene et al. 2009; Vaškaitis, Arminienè, 2013), include many participants contributing to product development and network management. The application of information systems improve a company's activities, coordinates functional and business lines, increases the competitiveness in the tourism business and promotes a greater flow of tourists.

Modern information systems strategically help organizations make the right decisions, and, thanks to them, tourist regions can realize everything they have got by presenting themselves to potential tourists: museums, architectural monuments, various cultural and sporting events, festivals, and other activities. Therefore, in order to maintain a high level of customer service, it is necessary to analyze the possibilities of information systems applications.

Tourism contributed around US $\$ 19.7$ billion to GDP in 2019. In 2018, Indonesia received 15.8 million visitors, a growth of $12.5 \%$ from last year, and received an average receipt of US\$967. China, Singapore, Malaysia, Australia, and Japan are the top five sources of visitors to Indonesia. Since 2011, Wonderful Indonesia has been the slogan of the country's international marketing campaign to promote tourism.

Raja Ampat Islands, West Papua, has the highest recorded level of diversity in marine life, according to Conservation International.

Nature and culture are prime attractions of Indonesian tourism. The former can boast a unique combination of a tropical climate, a vast archipelago, and a long stretch of beaches, and the latter complement those with a rich cultural heritage reflecting Indonesia's dynamic history and ethnic diversity. Indonesia has a well-preserved natural ecosystem with rain forests that stretch over about 57\% of Indonesia's land (225 million acres). Forests on Sumatra and Kalimantan are examples of popular destinations, such as the Orangutan wildlife reserve. Moreover, Indonesia has one of the world's longest coastlines, measuring 54,716 kilometres (33,999 mi). The ancient Borobudur and Prambanan temples, as well as Toraja and Bali with their traditional festivities, are some of the popular destinations for cultural tourism.

Indonesia has nine UNESCO World Heritage Sites, including the Komodo National Park and the Sawahlunto Coal Mine; and a further 19 in a tentative list that includes Bunaken National Park and Raja Ampat Islands. Other attractions include the specific points in Indonesian history, such as the colonial heritage of the Dutch East Indies in the old towns of Jakarta and Semarang and the royal palaces of Pagaruyung, Ubud, and Yogyakarta.

\section{LITERATURE REVIEW}

\subsection{Database System}

A database system is basically just a computerized record-keeping system. The database itself can be regarded as a kind of electronic filing cabinet. It is repository or container for a collection 
of computerized data files. Users of the system can perform (or request the system to perform, rather) a variety of operations involving such files, for example :

- Adding new files to the database

- Inserting data into existing files

- Retrieving data from existing files

- Deleting data from existing files

- Changing data in existing files

The function of the DBMS or Database Management System in the development of important applications and systems in the world is very much. At present various large companies, both National and International, are utilizing databases to support their application systems. There are many very popular DBMS such as Oracle, Microsoft SQL Server, MySQL, PostgreSQL, Microsoft Access, IBM DB2, and many more. This computer software is for data processing and as an interface to make it easy for someone to manipulate the database. But many people are still confused between the database and the DBMS itself, even though both are different. There are at least 10 DBMS functions in helping to maintain and maintain data integrity in a system.

DBMS Benefits: a. The practicality of the DBMS provides small, permanent storage media $b$. Speed. c. Retrieve data quickly, practically d. Increase data security e. Reducing boredom $\mathrm{f}$. Update to date g. Makes it easy for users to gather information from data sets $h$. Reducing data duplication or data redundancy i. Improve data security $\mathrm{j}$. Makes it easy for users to gather information from data sets $\mathrm{k}$. Increasing data maintenance through data independence Weaknesses of DBMS include: a. Costs The need to get the right software and hardware is quite expensive b. Employ and maintain a DBA c. Very complex. d. Requires a certain skill to be able to do database administration and management so that optimal structure and data relations can be obtained. e. Requires storage capacity both external disc and internal memory so that the DBMS can work fast and efficiently. f. The need for resource resources is usually quite high.

\subsection{Internet}

The Internet is evolving - in its use and in its technology. Born from the vision to create an open infrastructure to network computers across the world, the Internet has become a socio-economic backbone of our society, with countless private and business users as well as governments relying on it on a daily basis. The drivers for this evolution are a mix of emerging players with diverse and potentially changing interests, be it users, operators, manufacturers, service and content providers, together with advances in technology that have become available over the years.

Yet, the Internet was designed to provide a simple and transparent end-to-end transfer service across a heterogeneous wired network infrastructure, allowing the exchange of information between two or more communication endpoints. Its early applications were remote login and file transfer before the World Wide Web (WWW) emerged as the main driver for the Internet's current success. Today the Internet is dominated by a variety of different applications, mainly concerned with human centric information exchange, such as e-mail or the access of hypertext documents, audio and video files or real-time multimedia communications. Besides its applications, the infrastructure of the Internet is also evolving, extending its reach to mobile users and end-devices with the inclusion of next generation mobile networks. This evolution of 


\section{International Journal of Business Management and Economic Review}

Vol. 4, No. 04; 2021

ISSN: 2581-4664

the Internet has lead to a patchwork of fixes that are now telling the tale and are requiring a rethink of the fundamental pillars of the Internet Architecture.

The Internet is the decisive technology of the Information Age, as the electrical engine was the vector of technological transformation of the Industrial Age. This global network of computer networks, largely based nowadays on platforms of wireless communication, provides ubiquitous capacity of multimodal, interactive communication in chosen time, transcending space. The Internet is not really a new technology: its ancestor, the Arpanet, was first deployed in 1969 (Abbate 1999). But it was in the 1990s when it was privatized and released from the control of the U.S. Department of Commerce that it diffused around the world at extraordinary speed: in 1996 the first survey of Internet users counted about 40 million; in 2013 they are over 2.5 billion, with China accounting for the largest number of Internet users. Furthermore, for some time the spread of the Internet was limited by the difficulty to lay out land-based telecommunications infrastructure in the emerging countries. This has changed with the explosion of wireless communication in the early twenty-first century. Indeed, in 1991, there were about 16 million subscribers of wireless devices in the world, in 2013 they are close to 7 billion (in a planet of 7.7 billion human beings). Counting on the family and village uses of mobile phones, and taking into consideration the limited use of these devices among children under five years of age, we can say that humankind is now almost entirely connected, albeit with great levels of inequality in the bandwidth as well as in the efficiency and price of the service.

Internet is a technology of freedom, in the terms coined by Ithiel de Sola Pool in 1973, coming from a libertarian culture, paradoxically financed by the Pentagon for the benefit of scientists, engineers, and their students, with no direct military application in mind (Castells 2001). The expansion of the Internet from the mid-1990s onward resulted from the combination of three main factors:

- The technological discovery of the World Wide Web by Tim Berners-Lee and his willingness to distribute the source code to improve it by the open-source contribution of a global community of users, in continuity with the openness of the TCP/IP Internet protocols. The web keeps running under the same principle of open source. And twothirds of web servers are operated by Apache, an open-source server program.

- Institutional change in the management of the Internet, keeping it under the loose management of the global Internet community, privatizing it, and allowing both commercial uses and cooperative uses.

- Major changes in social structure, culture, and social behavior: networking as a prevalent organizational form; individuation as the main orientation of social behavior; and the culture of autonomy as the culture of the network society.

\subsection{E- Tourism}

Contemporary tourism is often referred to as a "hybrid industry" due to its perfect combination and blending with Information and communication technologies (ICTs). Th is inevitably leads to the rise of e-tourism in the latest 90 -ies of the previous century and its significant growth in the coming decades of the 21 st century. Th e modern e-tourism system is quite dynamic and inevitably connected with the progress and development of ICTs (Pan, 2015). As a result, a diversified toolbox and services, supporting and supplying, accelerating the global interactions 


\section{International Journal of Business Management and Economic Review}

Vol. 4, No. 04; 2021

ISSN: 2581-4664

among the participating elements of the system come into action (Băbăiţă, Ispas, Ghenescu\&Hălălău, 2010). Travel and tourism industry are constantly changing and evolving due to the mergers and inosculation with the ICTs (Buhalis, 2003; O'Connor \& Murphy, 2004; Buhalis \& O'Connor, 2005; Law \&Jogaratnam, 2005). Th e process of integration has been additionally stimulated by the great potential, unique characteristics and influence of the Internet in the recent decades (Buhalis\& Law, 2008).

E-tourism system comprise electronic distribution of tourist information on services and products, exerting considerable influence upon contemporary consumer behaviour and his transition to e-tourist. Following the thread of thoughts, there are publications exploring factors and determinants, identifying consumers' apprehension and behaviour towards e-tourism services (Bajpai\& Lee, 2015), as well as their protection while purchasing online travel services and products (Nedelea\&Bălan, 2010). Generation of stimulus, information search and service quality influence consumer loyalty. Th e combination of factors affects and determines consumer behaviour and inclinations towards e-tourism services for travel planning purposes. Dimensions of e-travel service quality have been identified and key elements of which are: information quality; security; web site functionality; customer relationships; responsiveness (Ho \& Lee, 2007). These elements and the interactions between them determine online customer satisfaction and loyalty intention.

The functioning of the contemporary tourism system and its future seem unthinkable without the technological innovation, corresponding to the current conditions of the business environment, being the result of the ICTs development and wide use of the Internet. In this way of speaking, while identifying the nature and definition of e-tourism, some authors present it as a form of ICTs application in the travel and tourism industry, a way to establish and maintain trade relationships (mainly sales) in the global network in order to supply goods and services to the end consumer (Condratov, 2013). E-tourism is an innovative method greatly influencing consumer behaviour. Its growth is basically determined by the interactions between the tourism organization, consumer and the government (Nedelea\&Bălan, 2010).

One of the most cited definitions on the topic states: "e-tourism reflects the digitalization of all processes and value chains in the tourism, travel, hospitality and catering industries" (Buhalis, 2003, p. 76). Th e author suggests two distinct aspects while defining e-tourism: operational (tactical) and strategic. Th e operational plan proclaims that e-tourism comprises e-commerce ICTs in order to maximize its internal efficiency and the effectiveness of the travel and tourism companies. Th e main idea plots the suggestion that the use of technology is about to increase the effectiveness of the entire tourism system and to make the transition to the overall automation and digitalization of the process. Th e strategic aspect of the heading plots e-tourism as a thorough change, revolutionizing all business processes, the entire value chain, as well as the long-term interaction of the tourism organizations and the stakeholders concerned.

Recent social trends have led to the erosion of large narratives and the emergence of many historical views. New digital guidelines must overcome this challenge to develop tourism products that are relevant to different market segments. Tourism is an important wealth creator at the global and local level. The appropriate diffusion of information and communication technology (ICT) in this sector can increase social and economic impacts, from which many citizens and organizations in developed and developing countries can benefit, so that digital tourism can provide digital support from tourism experiences .The rapid adoption of cellular and 


\section{International Journal of Business Management and Economic Review}

Vol. 4, No. 04; 2021

ISSN: 2581-4664

digital technology has changed the experience of cityvisits. Tourism providers in destinations must collaborate inproviding services to develop services provided to meet theneeds of tourists and remain competitive. By providinginnovative technology-based services, Digital Tourism hasbecome a tourism service so that the Digital Revolution hascaused an emergency of the need for knowledge andinformation, can be facilitated to innovate from tourismactivities so that it is needed [26, 27]. Digital Tourism willsupport the concept of e-Tourism will help owners anddevelopers to manage tourist destinations that will bepromoted through digital applications, Digital Tourism canprovide information about tourist destinations with variousneeds and supporting facilities for tourism users.

\section{ANALYSIS AND DISCUSSION}

One of the E-Tourism websites in Indonesia is www.my-indonesia.info. It can be seen in the website that the application E-Tourism in Indonesia is still limited to provide tourism information through internet, and it is still far from the real E-Tourism concepts. E-Tourism does not only provide tourism information but also provide online booking, and so on. Based on the fact about the application of E-Tourism in Indonesia, it can be concluded that much improvement especially about the content E-Tourism website in Indonesia is needed. Andeka (2006) offered a concept of ETourism which cover online booking (2006) accommodation, tourist objects, activities and facilities, events, and transportation. The concept proposed by Andeka (2006) can be used as an example of a better ETourism in Indonesia. Every tourist faces the problems of time and money constraints in choosing a tourist object. they face the problems of accommodation, the choice of the objects, transportation and so on. It is impossible to take care of all the problems by him/herself. Therefore, Andeka offers the online booking concept. $\mathrm{He}$ also offers the concept of online booking packages where everything is taken care of the convenience of tourists.

E-Tourism in Indonesia is limited to providing information and the majority is still managed by local as well as central government. In fact, it should be managed by product and service providers such as travel agents, hotels, handicraft industry in order to [provide informative, fast, accurate websites that can cater the needs of tourists or prospective ones. There should be a paradigm shift that the development of E-Tourism should not be the responsibility of the government only, but it should also be the responsibility of those involved in the business The development of E-Tourism can be started by giving trainings to those involved in the tourism business. Providing technical assistance is also very much needed. At the beginning, the roles of the government will be dominant since in general the concept of ETourism and the use of ICT is still something novel for most people.

\section{CONCLUSION}

In the current Global Era Management Information Systems are an inseparable part of an organization where information systems that produce output (output) using input (input) and various processes needed to meet certain objectives in a management activity. Database management system is software that can be used to define, create, manage and control database access. An effective Information System provides accurate, timely and relevant information to users so that it can be used for decision making. In making decisions, both in daily operations, as well as in strategic planning into the future. The decision-making process must be based on 


\section{International Journal of Business Management and Economic Review}

Vol. 4, No. 04; 2021

ISSN: 2581-4664

timely and appropriate data and information so that the decisions taken are on target. Information is obtained from data processing, and data processing is carried out by information systems with the support of information technology. Data is raw material information and is collected ina database (database) so that collection, storage, maintenance, processing, and security can be carried out effectively and efficiently data management is needed, so that such information can be the right information, on time, accurate and relevant. For example, an academic institution must build an academic database, at least containing student data, lecturer data, course data, room data, schedules, so that appropriate information can be obtained about the academic organization of the institution. Thus, so that an effective database can be built, basic knowledge of databases and Database Management Systems is needed. Database management systems organize the volume of large amounts of data used by companies in their daily transactions. Data must be organized so that managers can find certain data easily and quickly to make decisions. The company breakdown the entire collection of data into a set of interconnected data tables, these small collections of interconnected data will reduce repetition of data so that the consistency and accuracy of feeding data ultimately increases. Today most companies use databases that follow a relational structure. Two important reasons behind the use of this structure are that the structure of the relational database is easy to use and the relationships between tables in the structure are implicit. The ease of use has encouraged many managers to become direct users and database resources. Increasing the importance of database asa resource that supports decision making has required managers to learn more about the design of database use. Inthis paper the author will try to explain how the database management system.

Tourism sector is one of the sectors in Indonesia that generates huge income and its 2010 Hussein, et al. 199 development cannot be divorced from the roles of small and medium scale business (SME). With the development of science and technology, tourism sector cannot be separated from the use of E-Tourism. However, the development of E-Tourism support Indonesia's tourism cannot be done well. maksimal. The development of E-Tourism in Indonesia is left behind compared to that in Singapura, Malaysia, and Thailand. The weaknesses of ETourism application lies in the unavailability of tourism information in Indonesia Besides, the use of ICT inETourism concept is still very shallow, that is, it is limited to providing tourism information without adding value added such as online booking and so on. ICT in Indonesia is still developed by the government, not by the businessmen involved.

\section{REFERENCE}

Boyd, Danah M., and Nicole B. Ellison. "Social Network Sites: Definition, History, and Scholarship." Journal of Computer-Mediated Communication 13, no. 1 (2007).

Brandão, F., \& Costa, C. (2012). Regional Innovation Systems and Tourism: a Conceptual Approach. Revista Turismo e Desenvolvimento, 17/18(2), 647-660.

Castells, Manuel. (2018). "The Impact of the Internet on Society: A Global Perspective". University of Southern California.

Ho, Ch. \& Lee, Y. (2007). The development of an e-travel service quality scale. Tourism Management, 28(6), 1434-1449.

Jennings, G. (2001). Tourism Research. Australia: John Wiley \& Sons.

Jonathan, C. \& Tarigan, R. (2016). The Eff ects of E-tourism to the Development of Tourism 


\section{International Journal of Business Management and Economic Review}

Vol. 4, No. 04; 2021

ISSN: 2581-4664

Sector in Indonesia. CommIT (Communication \& Information Technology) Journal, 10(2), 59-62.

J. Ortiz, M. Balazinska, J. Gehrke, and S. S. Keerthi. Learning state representations for query optimization with deep reinforcement learning. In Proceedings of the Second Workshop on Data Management for End-To-End Machine Learning, DEEM'18, pages 4:1-4:4, New York, NY, USA, 2018. ACM.

Karnouskos, S., Daras, P., Presser, M. \& Baker, N. (2008). "Real Word Internet". Position Paper.

Kazandzhieva, Velina \& Santana, Hristina.(2019). E-tourism : Definition, development and conceptual framework.

Malciene, Dr.Zita., Skaurone, Laima. (2019). "Application of Information Systems in Tourism and Leisure Sector". Lithuania: Panevezys University of Applied Sciences.

Mattsson, J., Sundbo, J., \& Fussing-Jensen, C. (2005). Innovation Systems in Tourism: The Roles of Attractors and Scene-Takers. Industry \& Innovation, 12(3), 357-381.

Molina-Morales, F. X., \& Martínez-Fernández, M. T. (2010). Social Networks: Effects of Social Capital on Firm Innovation. Journal of Small Business Management, 48(2), 258-279.

O'Connor, P. (2003). Online Intermediaries - Revolutionizing Travel Distribution. Travel \& Tourism Analyst, 1, 3-21.

Pan, B. (2015). E-tourism. Entry in Encyclopedia of tourism. New York: Springer.

Sezin, E. (2016). e-Consumers in the Era of New Tourism. Singapore: Springer.

S. Idreos, K. Zoumpatianos, M. Athanassoulis, N. Dayan, B. Hentschel, M. S. Kester, D. Guo, L. M. Maas, W. Qin, A. Wasay, and Y. Sun. The periodic table of data structures. IEEE Data Eng. Bull., 41(3):64-75, 2018

S. Idreos, K. Zoumpatianos, B. Hentschel, M. S. Kester, and D. Guo. The data calculator: Data structure design and cost synthesis from first principles and learned cost models. In Proceedings of the 2018 International Conference on Management of Data, SIGMOD Conference 2018, Houston, TX, USA, June 10-15, 2018, pages 535-550, 2018.

Susanto, Azhar \& Meiryani. (2019). "Database Management System".

Tan, P.-N., Steinbach, M.; Kumar, V. (2005): "Introduction to data mining". Boston: Pearson Addison Wesley.

WTO. (2007). A practical guide to tourism destination management. Madrid: Author 